\title{
Letramento digital na Educação de Jovens e Adultos: uma experiência no Colégio de Aplicação da UFRGS
}

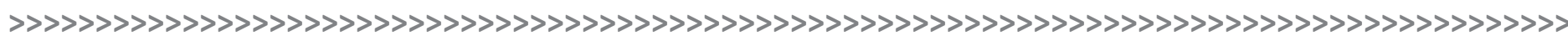

Daiane Martins Bocasanta*

Clevi Elena Rapkiewicz**

\section{Resumo:}

O presente relato de experiência tem como objetivo descrever atividades pedagógicas de letramento digital realizadas com alunos de uma turma de alfabetização e pós-alfabetização da Educação de Jovens e Adultos (EJA), de uma escola pública federal de Porto Alegre (RS). Tais atividades foram elaboradas a partir de um diagnóstico inicial das necessidades da turma, numa parceria estabelecida entre a professora polivalente (pedagoga) e a professora de Cultura Digital. O planejamento, posto em prática durante o primeiro semestre do ano de 2019 , esteve centrado em atividades que desmistificassem o uso de tecnologias digitais, tais como computadores e smartphones. Do mesmo modo, as professoras também privilegiaram o reaproveitamento de lixo eletrônico, na desmontagem de artefatos (mouses e teclados, entre outros) para o entendimento do funcionamento dos mesmos e na ressignificação desses na produção de novos objetos, como um alfabeto para a sala de aula e jogos pedagógicos.

\section{Palavras-chave:}

Educação de Jovens e Adultos. Tecnologias digitais. Lixo eletrônico.

\begin{abstract}
:
The present experience report aims to describe pedagogical activities of digital literacy carried out with students of a literacy and post-literacy class of Youth and Adult Education, from a federal public school in Porto Alegre (RS). Such activities were developed based on an initial diagnosis of the needs of the class, in a partnership established between the multipurpose teacher (pedagogue) and the Digital Culture teacher. The planning put into practice during the first half of 2019, was centered on activities that demystify the use of digital technologies, such as computers and smartphones. In the same way, the teachers also favored the reuse of electronic waste, in the disassembly of artifacts (mouses and keyboards, among others) to understand their functioning and to redefine them in the production of new objects, such as an alphabet for the classroom and pedagogical games.
\end{abstract}

\section{Keywords:}

Youth and Adult Education. Digital technologies. Eletronic waste.

\section{Introdução}

Muitas mudanças vêm marcando nosso modo de vida atual de forma vertiginosa. A cada dia que passa, surgem novos dispositivos com os quais podemos gerenciar cada segundo de nossas vidas e nos conectar em tempo real com outras pessoas. E, desse
* > Pedagoga, Mestre e Doutora em Educação. Professora Polivalente da Educação de Jovens e Adultos do Colégio de Aplicação da UFRGS. E-mail: professoradaianecap@gmail.com.

** > Doutora em Engenharia de Sistemas e Computação (COPPE/UFRJ, 1998). Professora de Informática, Colégio de Aplicação da UFRGS. E-mail: clevi@ufrgs.br. 
processo, ninguém passa incólume, independentemente de seu grau de escolarização. O entendimento do contexto que vivemos na contemporaneidade e a melhoria da qualidade de vida e de comunicação de todos, portanto, passa pela possibilidade de compreensão do funcionamento das engrenagens que hoje nos movimentam - mesmo àqueles que não tem acesso ou o hábito de manusear algum tipo de artefato digital em seu cotidiano. Desse modo, o trabalho a que por ora nos dedicamos, trata-se de um relato de experiência acerca de um projeto de ensino centrado em atividades de letramento digital realizado em uma turma de Anos Iniciais do Ensino Fundamental da Educação de Jovens e Adultos (EJA).

Tal relato contempla práticas pedagógicas ocorridas em uma escola pública federal de Porto Alegre/RS, durante o primeiro semestre de 2019. Essa experiência, gestada e desenvolvida em uma parceria firmada entre a professora polivalente da turma (pedagoga) e a professora responsável pela disciplina Cultura Digital teve como participantes um grupo de quatro estudantes com idades entre 37 e 68 anos, sendo uma mulher e três homens. Os alunos da turma tinham diferentes ocupações fora do âmbito escolar. Sendo assim, o aluno de 68 anos, apesar de aposentado, continuava atuando como zelador/porteiro de um condomínio. Outro aluno, de 40 anos, era porteiro ligado a uma empresa terceirizada que prestava serviços à universidade à qual a escola é vinculada. O terceiro aluno, com 41 anos, também era funcionário terceirizado, porém desenvolvendo atividades na supervisão da jardinagem da universidade. E, por último, a única mulher da turma, com 37 anos, trabalhava como cuidadora de idosos. Dois dos alunos ainda estavam em processo de alfabetização e dois estavam mais adiantados em sua trajetória de escolarização.

Alguns estudantes já possuíam algum conhecimento no uso de artefatos digitais como computadores e smartphones. No entanto, tais conhecimentos eram restritos ao uso de redes sociais, câmera fotográfica e aplicativos de troca de mensagens. Como podemos observar nas atividades laborais dos alunos, o uso de computadores não era uma demanda efetiva em seus locais de trabalho. Entretanto, os sujeitos manifestavam o desejo de aprender mais sobre isso e até quem sabe, utilizar tais conhecimentos para conseguir galgar outras posições no mercado de trabalho. Desse modo, as aulas de Cultura Digital, que ocupavam duas horas/aula semanais, eram momentos ansiosamente aguardados pelos estudantes, frente a possibilidade de ampliação desse repertório. Como já mencionamos em outra pesquisa (BOCASANTA; WANDERER; KNIJNIK, 2019) é possível observar que, no contexto da EJA, na escola em questão, os alunos frequentemente creditavam um caráter salvacionista ao domínio de conhecimentos de ordem tecnocientífica:

Os estudantes expressaram estar fortemente marcados pela ideia de que se apropriar da tecnociência é um imperativo na vida de todos: "A ciência e a tecnologia, pra mim, é uma evolução que veio pra mudar a vida das pessoas, nos traz possibilidades que jamais poderia imaginar, como pagar contas, fazer compras online...”; “É, hoje em dia é tudo informatizado, né? [...] A tecnologia está muito avançada, mas o maior problema é que a gente não tem oportunidade de aprender as inovações que vão mudando o mundo rapidamente. (BOCASANTA; WANDERER; KNIJNIK, 2019, p. 5).

Algumas discussões, tais como a que desenvolve Bernadette Bensaude-Vincent (2013) na obra As vertigens da tecnociência nos levam a refletir acerca do papel da tecnociência no mundo atual. Para a autora, apesar de a tecnociência ter dentre seus traços definidores ser um processo globalizante, ela não seria um destino inexorável (BENSAUDE-VINCENT, 2013). Em sua argumentação, a autora estabelece a possibilidade de "civilizarmos" as tecnociências, a fim de criar um mundo sob tensão para resistir ao processo de uniformização (BENSAUDE-VINCENT, 2013). Da mesma forma que os programas tecnocientíficos 
contemporâneos incentivariam o individualismo e a atomização do tecido social, nossos esforços deveriam centrar-se em "requalificar a polis, a cidade, como a associação de indivíduos livres e independentes" (BENSAUDE-VINCENT, 2013, p. 223).

$\mathrm{Na}$ análise dos tempos que habitamos na atualidade, Lazzarato (2014) demarca que nossa sociedade contemporânea é maquinocêntrica. $\mathrm{O}$ capitalismo age sobre as subjetividades e desse modo, "à produção do sujeito ou da pessoa individuada se sobrepõem um tratamento inteiramente diferente e uma apreensão complemente outra da subjetividade, num processo de 'servidão maquínica' [...]” (LAZZARATO, 2014, p. 28). A servidão maquínica altera o status do indivíduo, que deixa de ser visto como "um 'sujeito individuado', 'um sujeito econômico' (capital humano, empresário de si mesmo) ou como “cidadão”" (LAZZARATO, 2014, p. 28). Nessa configuração, o indivíduo seria considerado uma engrenagem, parte componente de diferentes agenciamentos, tais como o sistema financeiro, empresa, mídia, Estado de bem-estar social, etc. Desse modo,

\footnotetext{
[a] sujeição fabrica um sujeito vinculado a um objeto externo (uma máquina, um dispositivo de comunicação, dinheiro, serviços públicos etc.), de que o sujeito faz uso e com o qual ele age. Na sujeição, o indivíduo trabalha ou se comunica com o outro sujeito individuado via uma máquina-objeto, que funciona como "meio" ou mediação de sua ação ou uso. A lógica "sujeito-objeto", que constitui o modo de funcionamento da sujeição social, é uma lógica "humana, demasiado humana”.

Em contrapartida, a servidão maquínica não se constrange com os dualismos sujeito/ objeto, palavras/coisas ou natureza/cultura. $\mathrm{O}$ dividual não se opõe às máquinas, nem faz uso de um objeto externo; ele é adjacente às máquinas. Juntos eles constituem um dispositivo "homens-máquinas" nos quais homens e máquinas são meras partes recorrentes e intercambiáveis de um processo de produção, comunicação, consumo etc. que os excede. (LAZZARATO, 2014, p. 29, grifo do autor).
}

Seguindo essa mesma linha de pensamento de Lazzarato (2014), que conecta diretamente máquinas e seres humanos, Paula Sibilia (2012) analisa o papel da escola na contemporaneidade, a partir da incompatibilidade entre sujeitos e escola. Sibilia (2012) argumenta que esse desencaixe entre alunos e escola tem se gestado há bastante tempo, ao longo de todo século XX, algo que vem se intensificando justamente "quando se está soldando um encaixe quase perfeito entre, de um lado, esses mesmos corpos e subjetividades e, de outro, um novo tipo de maquinaria, bem diferente da parafernália escolar e talvez oposta a ela" (SIBILIA, 2012, p. 14). Tal parafernália, adianta a autora, seriam os "aparelhos móveis de comunicação e informação, tais como os telefones celulares e os computadores portáteis com acesso à internet, que alargaram num abismo a fissura aberta há mais de meio século pela televisão e sua concomitante 'cultura audiovisual'” (SIBILIA, 2012, p. 14).

As considerações de Sibilia (2012) nos parecem muito pertinentes - e até recorrentes - quando falamos das gerações mais jovens, especialmente daqueles que Mark Prensky (2001) denominou nativos digitais, isto é, gerações formadas por pessoas que nasceram em meio a uma abundância de artefatos digitais e que "são todos 'falantes nativos' da linguagem digital dos computadores, vídeo games e internet” (PRENSKY, 2001, p. 2). Porém, quando falamos de alunos de Anos Iniciais da EJA - imigrantes digitais, na definição de Prensky (2001) - com idades avançadas, podemos afirmar que falamos de outra coisa. Algo que poderíamos dizer, pouco explorado.

Dudeney, Hockly e Pregum (2016) inferem que estamos formando estudantes para um futuro cujos contornos não estão muito claros. Não sabemos que profissões existirão nos próximos anos e, como argumentam os autores, existe um forte apelo por parte de governos, empregadores e pesquisadores, "para a promoção de habilidades próprias do século XXI, tais como criatividade e inovação, pensamento crítico e capacidade de 
resolução de problemas, colaboração e trabalho em equipe, autonomia e flexibilidade, aprendizagem permanente" (DUDENEY; HOCKLY; PREGUM, 2016, p. 17, grifo dos autores). E, ocupando a centralidade desse conjunto complexo de habilidades, estaria a capacidade de se envolver com as tecnologias digitais (DUDENEY; HOCKLY; PREGUM, 2016). Para tanto, os autores destacam a necessidade de envolver os alunos no domínio de letramentos digitais, definidos como: "habilidades individuais e sociais necessárias para interpretar, administrar, compartilhar e criar sentido eficazmente no âmbito dos canais de comunicação digital" (DUDENEY; HOCKLY; PREGUM, 2016, p. 17). Diferentes letramentos fariam parte desse conjunto, tais como letramento impresso, letramento em SMS, letramento em hipertexto, letramento em multimídia, letramento em jogos, letramento móvel, letramento em codificação, entre outros (DUDENEY; HOCKLY; PREGUM, 2016).

Nesse sentido, o trabalho propriamente dito, que passamos a descrever na seção seguinte, buscou aproximar e familiarizar os estudantes da turma de EJA com algumas tecnologias digitais, tomando como ponto de partida um diagnóstico inicial realizado com a turma e a perspectiva do letramento digital.

\section{Da proposta}

O relato de experiência aqui estruturado foi concebido a partir de uma metodologia de pesquisa qualitativa, inspirada na pesquisa-ação. Uma das premissas que guia essa escrita é a necessidade de contarmos nossas próprias histórias, a partir de nossos próprios pontos de vistas, afinal,

[s]e não contarmos nossas histórias a partir do lugar em nos encontramos, elas serão narradas desde outros lugares, aprisionando-nos em posições, territórios e significados que poderão comprometer amplamente nossas possibilidades de desconstruir os saberes que justificam o controle, a regulação e o governo das pessoas que não habitam espaços culturais hegemônicos. (COSTA, 2007, p. 92).

Buscando, portanto, nosso lugar e o lugar de nossos alunos nessa narrativa, que conta parte de uma história ocorrida numa sala de aula de EJA de uma escola pública, passamos a seguir para a descrição do que fizemos. Antes disso, porém, faz-se necessário traçarmos alguns balizamentos, visando justificar algumas escolhas pedagógicas. Assim, cabe destacar que o projeto ocorreu no primeiro semestre do ano de 2019. Primeiramente realizamos um diagnóstico acerca dos conhecimentos prévios do grupo, buscando definir nosso ponto de partida com cada aluno e identificar as dificuldades que cada um apresentava. Observamos que dentre os quatro alunos atendidos, todos portavam algum tipo de smartphone. No entanto, nem todos conheciam/sabiam utilizar as funcionalidades principais do aparelho. Um dos alunos, o mais idoso, com 68 anos, pedia constantemente ajuda da professora para usar o aparelho, inclusive quando queria mostrar fotos de netos ou mesmo receber fotos de atividades registradas no aparelho da professora. Esse mesmo estudante apresentava dificuldades bastante pronunciadas de coordenação motora fina, o que ficou evidente nas primeiras tentativas de uso do mouse. Visando sanar essas dificuldades, a professora de Cultura Digital sugeriu o "treinamento" do uso desse artefato através da simulação com um sabonete grande, em casa. Passadas algumas aulas, esse mesmo aluno, já com menos dificuldades, nos contou que tinha comprado o sabonete e que estava dedicando-se aos exercícios propostos em casa.

No geral, não tinham acesso a computadores em suas casas e apenas um deles já utilizava com maior desenvoltura buscadores de internet ou editores de texto. Ainda assim, como esse aluno descreveu, "eu não sei mexer nessas coisas, eu... tudo bem que eu mexo 
com computador mas eu não mexo muito, não sou nenhum hacker nenhum nerd que entra pra dentro do computador e vira do lado do avesso" (Aluno 1). A essas dificuldades, somavam-se o medo de lidar com artefatos digitais (especialmente de estragar algum aparelho da escola), dificuldades motoras (no que tange à motricidade fina exigida no manuseio do mouse e do teclado) e o nível de escolarização em que se encontravam, tendo em conta que dois dos alunos ainda estavam aprendendo a ler e escrever.

Concomitantemente ao diagnóstico que realizávamos em sala de aula, uma bolsista de graduação ligada à pesquisa realizada pelas professoras fez entrevistas com os estudantes, com a finalidade de ajudar a definir os rumos das práticas pedagógicas do semestre. Essas entrevistas foram importantes para a identificação de temáticas que seriam abordadas em sala de aula, tais como a problemática do lixo e os Direitos Humanos. A escolha da questão dos Direitos Humanos veio principalmente a partir de algumas inferências feitas pelos estudantes, que consideramos equivocadas e direcionadoras de práticas pedagógicas que pudessem ampliar tais entendimentos, como:

\begin{abstract}
Direitos humanos tá errado, totalmente errado. E vou te dizer o porquê ele tá errado. Não porque lá na frente eu quero ser um advogado, que eu quero ser um... um juiz, quero ser um promotor, "tendeu"? Mas baseado no cotidiano do dia a dia. Por exemplo, delinquente vem e te assalta tem mais direito que tu que é vítima. Batedor de carteira no centro de Porto Alegre, bate a tua carteira, tem mais direito do que tu que é vítima. Aí o cara vem mal intencionado, abusa de ti e tem mais direito por quê... do que tu que é vítima, do que você que é vítima. Tipo assim ó, direitos humanos, na minha concepção, no meu modo de ver, pra mim, é pra humano que é direito. Direitos humanos pra mim, no meu modo de ver, é pra aquele humano que levanta 4 horas da manhã e sai às 5 horas pra pegar o ônibus [...] (Aluno 1).
\end{abstract}

Pra mim, os direitos humanos são pros bandidos né. Eu acho. [...] Porque o cidadão de bem... o cidadão de bem tá, tá por conta do, da bandidagem né. Aí que tá. Tá vendo as mulheres hoje em dia tudo, quantas mulheres são morta aí. Então hoje... ah vamos supor que a pessoa tem um filho hoje, tem filho e que não pode dar uma palmada no filho que, que... e aí? Tudo isso influi. (Aluno 2).

Direitos humanos... ah, como é que eu vou te dizer... Direitos iguais pra todos né, tem mais, tem muito preconceito hoje em dia, por causa disso aí. (Aluno 3).

Feitos esses balizamentos iniciais, passamos à descrição das atividades propriamente ditas.

\title{
Funcionamento do teclado e construção de um quadro com o nome de cada aluno
}

Tendo observado as especificidades da turma, optou-se pela exploração de diferentes artefatos digitais descartados como lixo eletrônico. Entre outras coisas, essa escolha deu-se pela necessidade de desmistificar os artefatos digitais e para que os alunos perdessem o medo de utilizar os mesmos. Dessa forma os estudantes tiveram uma aula com a professora de Cultura Digital em que a mesma explicou o funcionamento de um teclado de computador. Visando demonstrar como funciona um teclado por dentro, foi proposta aos alunos a realização de um jogo de batalha naval em folhas fotocopiadas, com diagramas montados pelos próprios alunos, que puderam disputar partidas entre si e com as professoras e bolsistas.

Após, os sujeitos foram convidados a desmontar teclados, selecionar letras do próprio nome e montar quadros em pedaços de madeira previamente pintados por eles. Findada essa montagem, os alunos fizeram uma cruzadinha com palavras relacionadas ao teclado. 


\section{Construção de um alfabeto e de um jogo de memória com suporte em CD}

Em um planejamento de aulas, as professoras discutiram a necessidade de construção de um alfabeto para a sala de aula. Desse modo, surgiu a ideia de montar esse alfabeto com o uso de lixo eletrônico, especificamente com o reaproveitamento das bases de teclados desmontados. Essa construção demandou mais de um mês de aulas semanais. O primeiro passo foi definir junto aos estudantes as palavras que fariam parte do alfabeto. Essas palavras foram escritas pela professora pedagoga no quadro branco e registradas pelos alunos nos cadernos. Isso possibilitou a identificação de palavras que tivessem sentido para o grupo, englobando, por exemplo, insumos para a construção civil e ferramentas, tais como areia, martelo, pá e serrote. Deixar a cargo dos alunos a escolha das palavras para o alfabeto foi uma estratégia de não-infantilização do processo pedagógico voltado para adultos.

Subsequentemente, as palavras foram divididas entre os alunos, que digitaram as mesmas no computador, com o auxílio de professoras e bolsistas da graduação. As palavras digitadas foram então, usadas para pesquisas em bancos de imagens da internet. Cada aluno escolheu as imagens de acordo com as palavras que pesquisou e salvou em um arquivo. Os bolsistas organizaram as imagens, que foram impressas. Na aula seguinte, os alunos montaram o alfabeto, colando letras e imagens em bases de teclados e unindo as mesmas com fios de computador.

Foram utilizados ainda, fotogramas feitos a partir das letras iniciais de cada aluno e fotos registradas com smartphones, estilizadas em aplicativo próprio, com ajuda da professora e impressas em uma mini-impressora do tipo Sprocket da HP.

Utilizando as mesmas imagens impressas para o alfabeto, cada aluno também montou um jogo de memória letra/imagem tendo como suporte CDs. O jogo foi explorado em sala de aula e, após, cada um pode levar um exemplar para casa.

Concomitante a esse trabalho, explorou-se em sala de aula, obras e a biografia de Vik Muniz, importante artista plástico brasileiro que cria seus quadros especialmente a partir do reaproveitamento de diferentes tipos de lixo e de alimentos.

Figura 1 - Alfabeto da turma

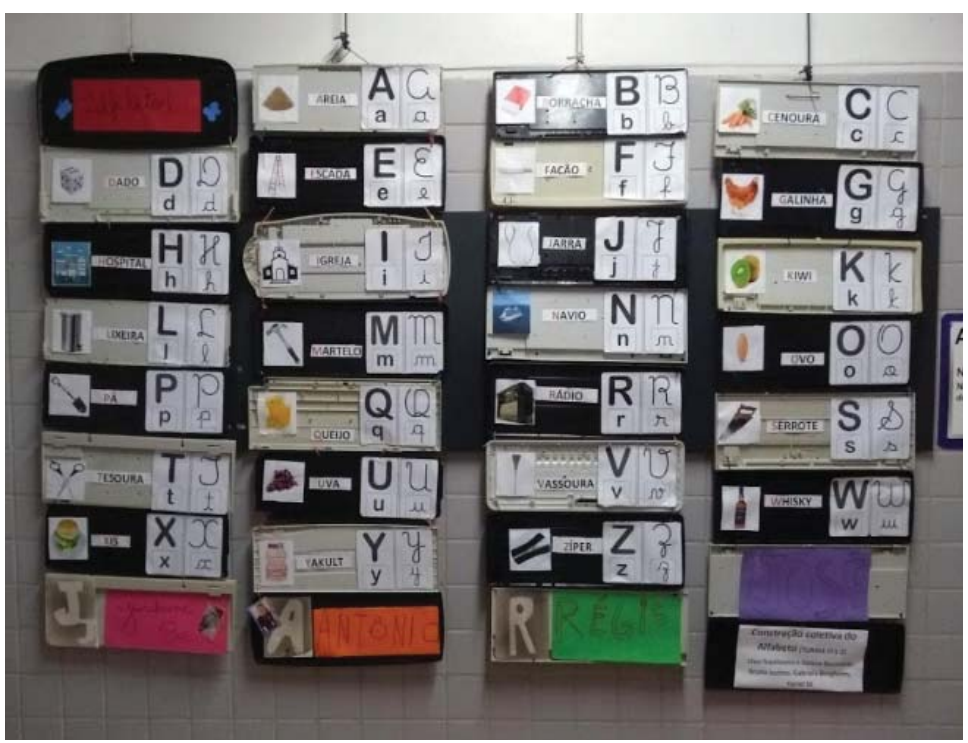

Fonte: Elaborada pelas autoras (2019). 
Figura 2 - Jogo da memória

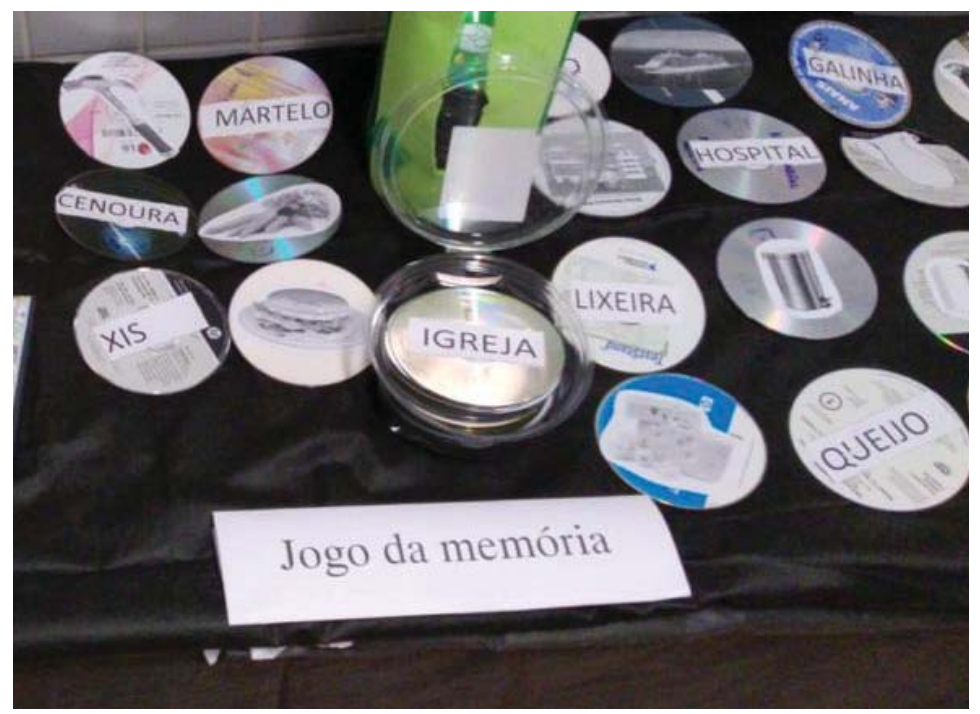

Fonte: Elaborada pelas autoras (2019).

\section{Funcionamento de monitores e imagem digital}

Como já havíamos adiantado ao fazermos os balizamentos que abriram essa seção, uma temática que guiou o planejamento das aulas do semestre foi o estudo da Declaração Universal dos Direitos Humanos. Sendo assim, após a explicação do funcionamento de monitores e sobre o pixel, os alunos escolheram imagens entre obras compostas por 30 artistas que ilustraram cada direito da Declaração Universal dos Direitos Humanos em um projeto que comemorou os 70 anos de sua publicação (MUTIRÃO, 2018). Após essa escolha, as imagens foram impressas em tamanho A4 e coloridas. A proposta feita aos estudantes consistiu em recortar as obras em quadrados e remontar, de forma livre e criativa as mesmas, colando-as em uma folha de papel colorida. Tendo finalizado a atividade, os alunos escanearam as imagens com a ajuda das professoras. As imagens escaneadas foram então, customizadas com a utilização do recurso Paint Brush. Assim, os alunos puderam adicionar fotos de si, de familiares e escrever seus próprios nomes. Essas obras foram impressas e serviram de capas em caixas de CDs, onde foram colocados impressos todos os direitos da Declaração Universal dos Direitos Humanos.

Figuras 3, 4 e 5 - Capas elaboradas pelos alunos através de releitura de imagens

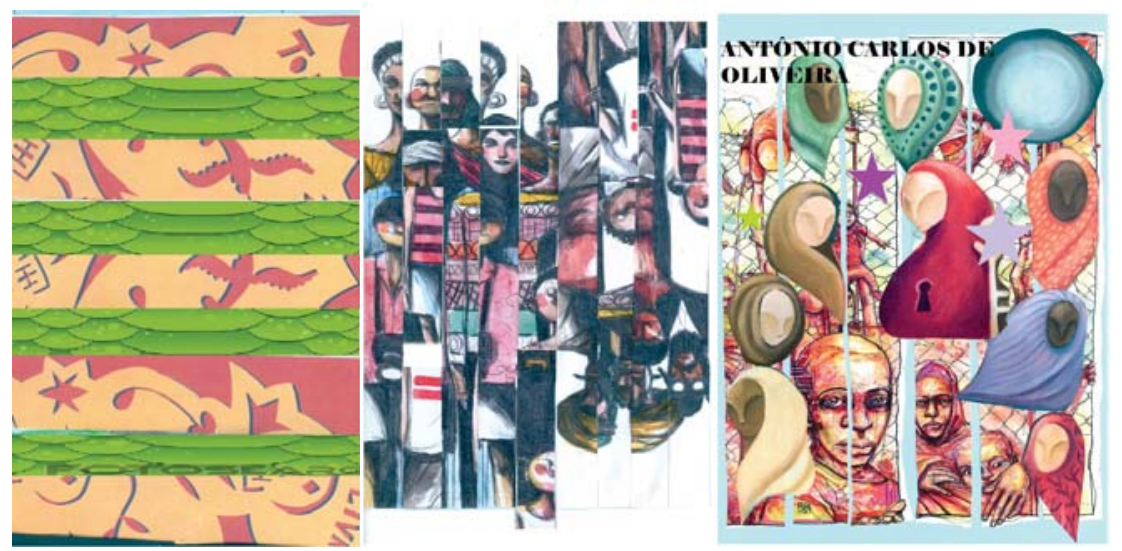

Fonte: Elaboradas pelas autoras (2019). 


\section{Considerações finais}

O trabalho que por ora descrevemos possibilitou a discussão do lugar das tecnologias digitais na sala de aula, em especial, quando esse espaço é ocupado majoritariamente por indivíduos na idade adulta. Vemos em algumas obras, como a de Paula Sibilia (2012), discussões centradas no descompasso entre a escola e os estudantes de hoje, isto é, jovens nascidos em meio a uma grande profusão de tecnologias digitais. Afinal, como argumentam Fernandes, Diniz e Barros (2016, p. 36):

Crianças e jovens de diversas escolas adentram-na com seus aparatos e utilizam-nos dentro do contexto escolar. Porém, não observamos que nem sempre o espaço da rede é considerado também como local de produção de cultura desses sujeitos culminando, assim, em embates e entraves, a partir da tentativa de separação entre as práticas culturais dos jovens que se dão dentro/fora da escola e o uso de dispositivos móveis em seu âmbito. Tais tensões nem sempre entendem o sujeito como sendo constituído através de sua relação com o seu tempo.

Esse enfoque na infância e juventude, ao falarmos em tecnologias digitais sustenta-se no paradigma vigente que posiciona o jovem como detentor desse tipo de conhecimento (BOCASANTA, 2013). Nesse sentido, boa parte das discussões centradas no cruzamento escola/tecnologias digitais, relega a segundo plano o que acontece quando o sujeito escolar já está na idade adulta ou ainda, na terceira idade. Acreditamos, portanto, que esse relato de experiência pode ser inspirador para outros educadores, visando ampliar a realização de escolhas pedagógicas que possibilitem a estudantes da EJA o acesso a tecnologias digitais.

Pudemos observar ao longo do processo, o envolvimento dos estudantes nas aulas de Cultura Digital e o quanto a intersecção entre duas diferentes disciplinas pode ser benéfica para o processo de alfabetização e pós-alfabetização na Educação de Jovens e Adultos. Dentre os principais resultados obtidos, foi possível verificar que ao final do semestre os alunos mostravam-se mais familiarizados com o uso de tecnologias digitais e menos receosos de "estragar" os equipamentos disponibilizados em aula. A cada atividade proposta, foi gratificante observar a satisfação dos estudantes frente a cada pequena conquista, como utilizar de forma mais autônoma o mouse ou mesmo, localizar as letras do próprio nome no teclado.

Outro aspecto que não podemos deixar de destacar, é que o trabalho realizado em sala de aula também esteve focado na discussão acerca do descarte e do reaproveitamento de lixo eletrônico. Vivemos em um contexto marcado por acentuadas mudanças climáticas e degradação do meio ambiente, provocadas sobretudo pela ação humana. Sendo assim, faz-se relevante trazermos essas questões para a sala de aula. 


\section{Referências}

MUTIRÃO. 70 anos da Declaração dos Direitos Humanos. [S.l.]: Mutirão, 2018. Disponível em: https://www.direitoshumanos70anos.com/?fbclid=IwAR0CKdZwBtdAcqbMERA0_chHjhzJ0K-_ Dh9VwU5KfH4s1DWV55ZqaVoAcr0. Acesso em: 18 out. 2019.

BENSAUDE-VINCENT, Bernadette. As vertigens da tecnociência: moldar o mundo átomo por átomo. São Paulo: Idéias \& Letras, 2013.

BOCASANTA, Daiane Martins. Dispositivo da tecnocientificidade: a iniciação científica ao alcance de todos. 2013. 233 p. Tese (Doutorado em Educação) - Programa de Pós-Graduação em Educação, Universidade do Vale do Rio dos Sinos, São Leopoldo, 2013.

BOCASANTA, Daiane Martins; WANDERER, Fernanda; KNIJNIK, Gelsa. Dispositivo de tecnocientificidade e Educação de Jovens e Adultos. Educação (UFSM), Santa Maria, v. 44, p. e52, jul. 2019. ISSN 1984-6444. Disponível em: https://periodicos.ufsm.br/reveducacao/article/view/30910. Acesso em: 15 nov. 2019.

COSTA, Marisa Vorraber. Pesquisa-ação, pesquisa participativa e política cultural da identidade. In: COSTA, Marisa Vorraber (org.). Caminhos investigativos II: outros modos de pensar e fazer pesquisa em educação. 2. ed. Rio de Janeiro: Lamparina Editora, 2007. p. 91-116.

DUDENEY, Gavin; HOCKLY, Nicky; PREGUM, Mark. Letramentos digitais. São Paulo: Parábola Editorial, 2016.

FERNANDES, Adriana Hoffmann; DINIZ, Lucy Anna; BARROS, Raquel Silva. Mídias móveis, usos e redes: reflexões e desafios para a escola. In: AMARO, Ivan; SOARES, Maria da Conceição Silva (org.). Tecnologias digitais nas escolas: outras possibilidades para o conhecimento. Brasília, DF: CAPES, 2016. p. 29-44.

LAZZARATO, Maurizio. Signos, máquinas, subjetividades. São Paulo: Edições Sesc: N-1 Edições, 2014.

PRENSKY, Marc. Nativos digitais, imigrantes digitais. Tradução de Roberta de Souza. NCB University Press, Lincoln, v. 9, n. 5, out. 2001. Disponível em: http://www.colegiongeracao.com.br/ novageracao/2_intencoes/nativos.pdf. Acesso em: Acesso em: 15 nov. 2019.

SIBILIA, Paula. Redes ou paredes: a escola em tempos de dispersão. Rio de Janeiro: Contraponto, 2012. 
